$\begin{array}{ll}\text { Abstracta Iranica } & \begin{array}{l}\text { Abstracta Iranica } \\ \text { Revue bibliographique pour le domaine irano-aryen }\end{array} \\ & \text { Volume } \mathbf{2 4} \text { | } \mathbf{2 0 0 3} \\ \text { Comptes rendus des publications de } \mathbf{2 0 0 1}\end{array}$

\title{
Silk Road Art and Archaeology, 7, (2001), 310 p.
}

\author{
Étienne de La Vaissière
}

\section{(2) OpenEdition}

Journals

Édition électronique

URL : http://journals.openedition.org/abstractairanica/34161

DOI : 10.4000/abstractairanica.34161

ISSN : 1961-960X

Éditeur :

CNRS (UMR 7528 Mondes iraniens et indiens), Éditions de l'IFRI

Édition imprimée

Date de publication : 15 mai 2003

ISSN : 0240-8910

\section{Référence électronique}

Étienne de La Vaissière, "Silk Road Art and Archaeology, 7, (2001), 310 p. », Abstracta Iranica [En ligne], Volume 24 | 2003, document 8, mis en ligne le 05 janvier 2010, consulté le 25 septembre 2020. URL http://journals.openedition.org/abstractairanica/34161; DOI : https://doi.org/10.4000/ abstractairanica.34161

Ce document a été généré automatiquement le 25 septembre 2020.

Tous droits réservés 


\title{
Silk Road Art and Archaeology, 7, (2001), $310 \mathrm{p}$.
}

\author{
Étienne de La Vaissière
}

1 La plupart des articles de ce numéro sont intéressants pour les iranisants travaillant sur l'Antiquité :

2 - E. Kuzmina, «Pre-history of the Great Silk Road: Cultural Connections of Xinjiang Population with Andronovo Culture Tribes in the Bronze Epoch », pp. 1-21. L'A. montre le rôle décisif qu'a joué le Semiretch'e et la culture d'Andronovo dans la formation de la métallurgie dans le Xinjiang actuel (mais la notion de route de la soie n'a rien à voir làdedans).

3 - D. T. Potts, « Nana in Bactria », pp. 23-35. Après avoir souligné la stricte différence à faire entre Nana et Inanna/Ishtar, l'A. montre que Nana est associée au lion indépendamment d'Ishtar puis suggère, sur la base de sceaux du «Bactrian Margian Archaeological Complex » et après avoir établi la présence d'un culte de Nana à Suse dès le troisième millénaire av.n.è., que la présence en Bactriane de Nana pourrait remonter à la même période.

4 - M. Treister, "The Portrait of a Parthian King from the Samartian burial in the Don basin ", pp. 37-51. Par des comparaisons iconographiques, l'A. identifie le roi à Vologèse I (60-77 de n.è.) puis rappelle les diverses preuves archéologiques des contacts des Parthes et des Sarmates par le Caucase.

5 - A. Simonenko, "Chinese and East Asian Elements in Samartian Culture of the North Pontic Regio ", pp. 53-72. Une synthèse commode des découvertes très dispersées qui conduit l'A. à aborder la question de l'identité ethnique des Alains.

6 - S. A. Yatsenko, "The Costume of the Yuech-chihs: Kushans and its Analogies to the East and to the West », pp.73-120. Long article de synthèse sur la question, que l'on complètera par le chapitre correspondant de Litvinskij, B. A. (dir.), Vostočnyj Turkestan v drevnosti i rannem srednevekov'e. Arxitektura. Iskusstvo. Kostjum (voir le c.r. $\mathrm{n}^{\circ} 41$ pour les régions plus à l'est). 
7 - H. Falk, "The yuga of Sphujiddhvaja and the era of the Kuṣânas ", pp. 121-136 (voir le c.r. à part $\left.\mathrm{n}^{\circ} 37\right)$.

8 - B. A. Litvinsky, « Bactrian Ivory Plate with Hunting Scene from Temple of the Oxus », pp. 137-166. Publication d'une pièce d'ivoire inédite du Temple de l'Oxus provenant des fouilles dirigées par l'A. (voir également le c.r. $n^{\circ} 41$ ), comparaison avec d'autres plaques (Orlat, Takhti-Sangin qu'il date du $3^{\mathrm{e}} \mathrm{s}$.), et interprétation de l'ensemble.

9 - K. Tanabe, «A Kushano-Sasanian Silver Plate and central Asian Tigers », pp. 167-186. Le roi représenté serait Peroz I Khushanshah et les tigres, des tigres de la Caspienne. L'A. analyse ensuite les particularités des productions des ateliers kouchano-sassanides.

10 - J. Ya. Il'yasov, "The Hephtalite Terracotta", pp. 187-200 tente d'identifier un nouveau groupe de terracotta sur des critères iconographiques et propose de les attribuer aux Ephtalites.

INDEX

Thèmes : 1.2. Recueils d'articles : revues, colloques, ouvrages collectifs

\section{AUTEURS}

ÉTIENNE DE LA VAISSIÈRE

EPHE - ENS - Paris 